\title{
Dilatant till layer near the onset of streaming flow of Ice Stream C, West Antarctica, determined by AVO (amplitude vs offset) analysis
}

\author{
SRIDHAR ANANDAKRISHNAN \\ Department of Geosciences and EMS Environment Institute, The Pennsylvania State University, University Park, PA 16802-7501, U.S.A. \\ E-mail:sak@essc.psu.edu
}

\begin{abstract}
A powerful seismic technique that exploits the phase of the ice-bottom reflections shows that soft till is widespread beneath a West Antarctic ice stream very close to the onset of streaming flow. The amplitude vs offset (AVO) method measures the change in amplitude of the reflection as a function of increasing angle of incidence. For a decrease in acoustic impedance with depth, the reflection phase is negative at low angles of impedance but positive at intermediate angles. The change in phase by $180^{\circ}$ is an obvious and robust measure of the relative acoustic impedance contrasts. This technique is only usable when there is a change in phase vs offset, conditions which obtain for "UpB-type" tills (high water pressures and porosity, low compressional- and shear-wave velocities, similar to those observed at Upstream B camp). I have applied this technique to the far upstream regions of Ice Stream $\mathrm{C}$ and find that a dilatant (and presumably deforming), relatively thick (meters) till layer has formed beneath the ice stream within tens of $\mathrm{km}$ of the region identified as the transition from inland flow to ice-stream flow. These results suggest that the onset of rapid basal motion is linked to the formation of this deforming subglacial layer.
\end{abstract}

\section{INTRODUGTION}

Amplitude vs offset (AVO) analysis of seismic data is a powerful indicator of changes in physical properties with depth (see Sheriff and Geldart, 1995). The porosity, saturation (see Nolan and Echelmeyer, 1999) and the type of pore fluid are the primary controlling agents in the strength of the AVO effect. I report on a modification of the AVO technique that simplifies it and makes it more robust under some conditions. I calculate layer properties by measuring the incidence angle at which the reflection phase undergoes a $180^{\circ}$ shift.

The acoustic impedance of a water-saturated till is close to that of ice. A working hypothesis of active ice-stream flow is that subglacial till is mobilized, resulting in a meters-thick dilatant till layer that is pervasively sheared to produce fast flow (Alley and others, 1987a, b; Tulaczyk and others, 2001b). Such a layer would have significantly lower seismic velocities than a similar, non-dilatant, non-deforming layer (Blankenship and others, 1986). Distinguishing between these subglacial conditions is key to a fuller understanding of the ice-stream systems.

Measuring these basal conditions is possible, but difficult, with traditional seismic techniques that determine the compressional- and shear-wave seismic velocities $(\alpha$ and $\beta$, respectively) directly in the target layer by detecting a reflection from beneath the layer. Because of the thinness of the layer (on the order of a half-wavelength in the case of the deforming-till hypothesis), determining the seismic velocities of the layer directly by measuring the move-out of the layer-base reflection is difficult. Direct measurement of the layer velocities has been shown to be successful in one case (Blankenship and others, 1987), though generating the source shear waves is difficult. Another technique has been to measure the amplitude ratio between the primary and first multiple reflection and invert for the acoustic impedance of the layer (Smith, 1997). Both techniques require excellent signal-to-noise ratio and high frequencies, which are not always possible. Exploiting the phase reversal vs offset (when there is such a reversal) is a more robust technique.

This layer is thicker than about $5 \mathrm{~m}$ (a quarter-wavelength of our dominant frequency of $80 \mathrm{~Hz}$ ). Reflections from layers thinner than a quarter-wavelength would tend to average the reflectivity behavior of the upper and lower boundaries (see Nolan and Echelmeyer (1999) for a more detailed discussion).

Reflection seismic data were collected along a profile that crossed the southern margin of one of the tributaries that feed Ice Stream C (Fig. 1). This tributary (hereafter Cl) has sharp lateral boundaries (as identified by velocity data (Anandakrishnan and others, 1998; Joughin and others, 1999) and satellite imagery (Hodge and Doppelhammer, 1996)) but a relatively diffuse up-glacier boundary. The satellite imagery shows that distinct flowlines form downstream of a region of rough surface topography that is correlated to the edge of the sedimentary basin (Bell and others, 1998). The velocity data (Joughin and others, 1999) show that the relatively higher flow speeds that are associated with ice streaming extend farther into the interior of the ice sheet. Nevertheless, there is a change in the flow behavior of the ice as it crosses the up-glacier edge of the sedimentary basin: a flattening of the surface slope and reduction in driving stress (Bindschadler and others, 2001), the formation of distinct surface flow stripes (Hodge and Doppelhammer, 1996), a sharpening of the lateral boundary, and a narrowing of the main 


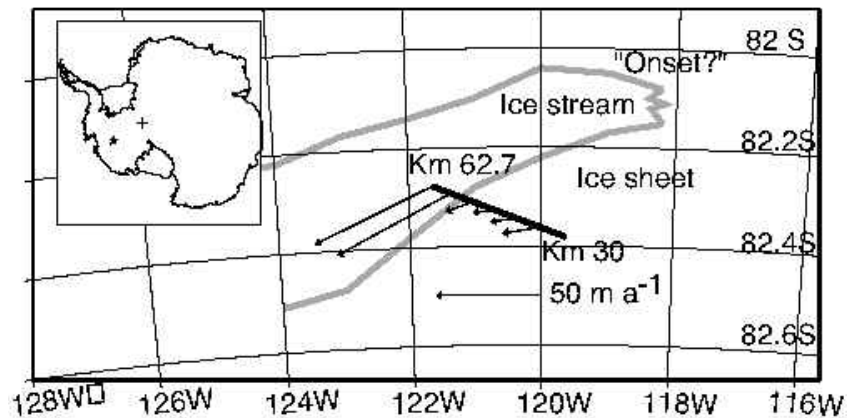

Fig. 1. Location map of part of the seismic line, including flow speeds. The boundaries of the ice stream are picked from satellite imagery.

flow zone, that suggest a distinct change that is associated with and possibly due to the presence of subglacial sediments. For this reason, I refer to this zone as the "onset" of this tributary of Ice Stream C (Bindschadler and others, 2001).

The seismic program consisted of collection of multifold reflection data using a towed snow streamer and gimballed geophones (Sen and others, 1998). The travel-time data have been analyzed and inverted for subglacial sedimentary structure (Anandakrishnan and others, 1998) and for internal-layer character (Burkett, 2000). Here I examine the AVO effect of the reflection data in which the compressionalwave reflectivity $R_{\mathrm{p}}(i)$ varies with $i$, the angle of incidence (defined as the angle of the seismic ray path relative to the reflection interface normal).

\section{REFLEGTIVITY THEORY}

The amplitude and phase of seismic reflections off interfaces between materials with distinct acoustic parameters (e.g. acoustic impedance, compressional-wave (P-wave) velocity $\alpha$, and shear-wave (S-wave) velocity $\beta$ ) can be strongly variable as a function of the ray path's angle of incidence. The normal-incidence P-wave reflectivity for a ray incident from the $i=1$ to the $i=2$ layer is

$$
R_{\mathrm{p} 0}=\frac{Z_{2}-Z_{1}}{Z_{2}+Z_{1}}
$$

where $Z_{i}=\rho_{i} \alpha_{i}$ is the acoustic impedance in the $i$ th layer. For this experiment, ice density is $\rho_{1}=920 \pm 20 \mathrm{~kg} \mathrm{~m}^{-3}$ and the $\mathrm{P}$-wave velocity is $\alpha_{1}=3831 \pm 15 \mathrm{~m} \mathrm{~s}^{-1}$ (Anandakrishnan and others, 1998). The normal-incidence reflection is positive or "normal" for $R_{\mathrm{p} 0}>0$, and negative or reversed for $R_{\mathrm{p} 0}<0$. The normal-incidence phase is reversed only if $Z_{2}<Z_{1}$. The range of densities and $\mathrm{P}$-wave velocities in the subglacial sediments, for which $Z_{2}<Z_{1}$, is small. For a realistic range of sediment densities $\left(1900-2200 \mathrm{~kg} \mathrm{~m}^{-3}\right)$, the velocities for which the normal-incidence reflection would be negative are $\alpha_{2}<1860 \mathrm{~m} \mathrm{~s}^{-1}$ to $\alpha_{2}<1600 \mathrm{~m} \mathrm{~s}^{-1}$, respectively. Though the density of these subglacial sediments has not been measured, farther downstream the density is $\rho=$ $1950 \mathrm{~kg} \mathrm{~m}^{-3}$, calculated from the reported density of solids of $2640 \mathrm{~kg} \mathrm{~m}^{-3}$ (Tulaczyk and others, 200la) and a porosity of $40 \%$. Thus the lower limit of $1900 \mathrm{~kg} \mathrm{~m}^{-3}$ and upper limit of $2200 \mathrm{~kg} \mathrm{~m}^{-3}$, corresponding to a porosity of $\approx 25 \%$, are reasonable.

The incidence-angle dependence of the reflection coefficient (calculated from the so-called Zoeppritz equations) is tabulated in the "scattering matrix" (Aki and Richards,

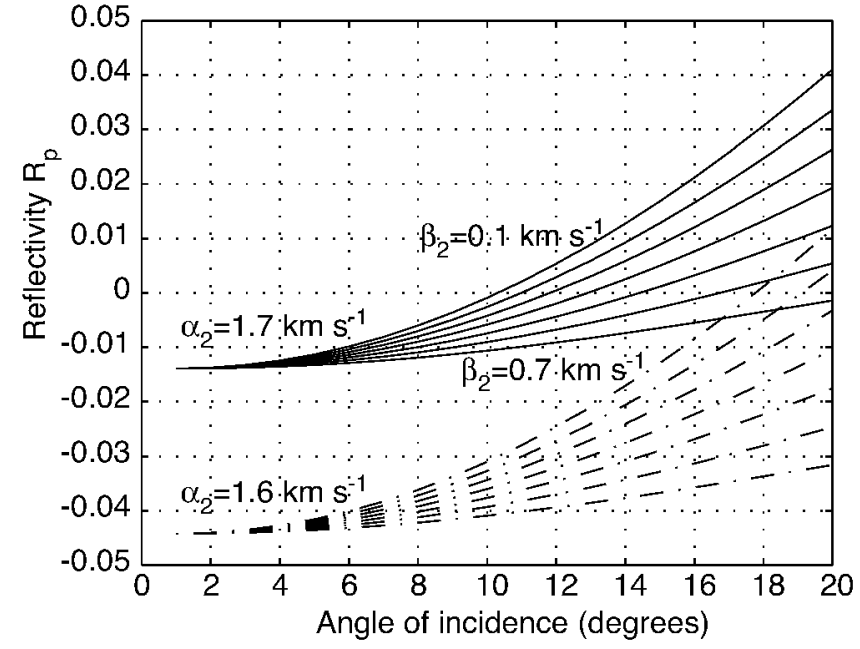

Fig. 2. Plot of reflection amplitude vs angle of incidence for ice over dilatant till: $\alpha_{1}=3.83 \mathrm{~km} \mathrm{~s}^{-1}, \beta_{1}=1.95 \mathrm{~km} \mathrm{~s}^{-1}, \rho_{1}=$ $920 \mathrm{~kg} \mathrm{~m}^{3}, \rho_{2}=2.1 \mathrm{~kg} \mathrm{~m}^{-3}$. For the upper set of curves, $\alpha_{2}=$ $1.7 \mathrm{~km} \mathrm{~s}^{-1}$ and for the lower set, $\alpha_{2}=1.6 \mathrm{~km} \mathrm{~s}^{-1}$. The shearwave velocity $\beta_{2}$ ranges from $0.1 \mathrm{~km} \mathrm{~s}^{-1}$ (upper curve) to $0.7 \mathrm{~km} \mathrm{~s}^{-1}$ (lower curve) in both sets of curves. The zero-crossing and $i_{\mathrm{c}}$ increases over that range.

1980), of which the $R_{\mathrm{p}}(i)$ reflectivity is a complicated function of $\mathrm{P}$ - and $\mathrm{S}$-wave velocities and densities in both layers. The AVO variation is particularly strong for reflection horizons that separate regions with large differences in Poisson's ratio $\sigma$ (Shuey, 1985). For a downward increase in Poisson's ratio, as would be the case for ice over unconsolidated sediments, $R_{\mathrm{p}}$ increases with increasing angle. Further, if the normal-incidence reflectivity is negative, then the reflection phase will change as the angle of incidence crosses the angle of intromission (the angle at which the reflection is extinguished). It is this "crossing angle" $i_{\mathrm{c}}$ that I measure and use to determine subglacial sediment properties.

Although I lack absolute reflection amplitudes, the AVO effect can be used to constrain the conditions at the bed of the ice. In particular, the reflection from the base of the ice stream has a distinct change in phase from negative at nearoffsets to positive at intermediate offsets if these conditions are met:

1. $R_{\mathrm{p} 0}<0$ because the acoustic impedance of the subglacial sediments is less than that of the ice; and

2. $\quad R_{\mathrm{p}}(i)>0$ for some $i$, with a crossing angle $i_{\mathrm{c}}$; this is most likely due to an increase in Poisson's ratio from the ice ( $\sigma=0.33)$ to the sediments $(\sigma \sim 0.45)$.

The crossing angle increases with increasing shear-wave velocity. For an assumed sediment P-wave velocity of $\alpha_{2}=$ $1.7 \mathrm{~km} \mathrm{~s}^{-1}$, the crossing angle ranges from $i_{\mathrm{c}}=11^{\circ}$ for $\beta_{2}=$ $0.1 \mathrm{~km} \mathrm{~s}^{-1}$ to $i_{\mathrm{c}}=25^{\circ}$ for $\beta_{2}=0.7 \mathrm{~km} \mathrm{~s}^{-1}$ (Fig. 2) (this is the likely range of $\mathrm{S}$-wave velocities in sediments (Hamilton, 1976)).

\section{FIELDWORK AND PROGESSING}

The analysis was conducted on shot gathers because of the low common-midpoint multiplicity (CMP fold); the trace spacing in all the figures is equal to the receiver spacing of $25 \mathrm{~m}$. We justify a posteriori the use of shot gathers rather than CMP gathers in the analysis. The region of interest for 


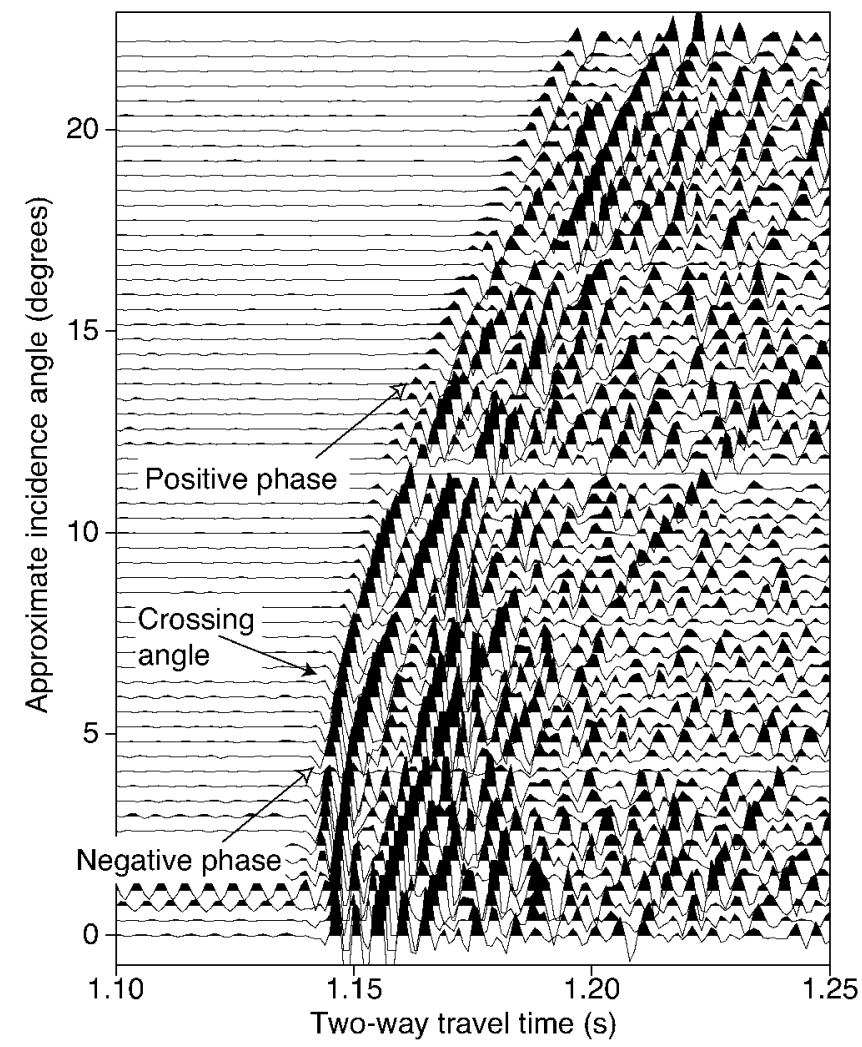

Fig. 3. Plot of a shot record from the ice stream at location $\mathrm{Km}$ 59.1. Each trace is separated by $25 \mathrm{~m}$; the trace label is approximate angle of incidence at the base of the ice sheet. The reflection energy at low angles of incidence has a negative "first break" - a trough. The first break at large angles is positive - a filled-in peak. The angle separating the two is the crossing angle. The uncertainty in choosing the crossing angle is 3-4 traces or $\pm 1.5^{\circ}$.

this study is of angles of incidence $i<15^{\circ}$. For those angles, the actual spread of reflection points at the base of the ice is $475 \mathrm{~m}$ at the maximum ice thickness of $H=1800 \mathrm{~m}$, and shorter yet in regions of thinner ice. I assume that bed conditions do not change with position at that scale.

\subsection{Normal-incidence reflectivity}

Previous analysis (Anandakrishnan and others, 1998) has shown that the subglacial structure has three distinct zones: crystalline basement $\left(\alpha_{2}=5.7 \mathrm{~km} \mathrm{~s}^{-1}\right)$ along most of the line outside the ice stream; sediments underlying slow-flowing, non-ice-stream ice for a short segment of the line from $\mathrm{Km}$ 33 to $\mathrm{Km} 42\left(\alpha_{2}<2.4 \mathrm{~km} \mathrm{~s}^{-1}\right.$, "ice-sheet sediments"); and sediments or till underlying fast-flowing ice-stream ice from $\mathrm{Km} 52$ to the end of the line $\left(\alpha_{2}<2.4 \mathrm{~km} \mathrm{~s}^{-1}\right.$, "ice-stream sediments"). I observe negative normal-incidence reflections $R_{\mathrm{p} 0}<0$ only within the body of the ice stream; along the rest of the line, $R_{\mathrm{p} 0}>0$.

This difference in $R_{\mathrm{p} 0}$ for the two sedimentary layers could be due to either a difference in density or a difference in P-wave velocity. The observed $R_{\mathrm{p} 0}<0$ implies that $Z_{2}<Z_{1}$ $=\rho_{1} v_{1}=3.524 \times 10^{6} \mathrm{~kg} \mathrm{~m}^{-2} \mathrm{~s}^{-1}$. For the range of assumed sediment densities of $1900<\rho_{2}<2200 \mathrm{~kg} \mathrm{~m}^{-3}$, the range of velocities is $1850>v_{2}>1600 \mathrm{~m} \mathrm{~s}^{-1}$. Thus, the ice-sheet sediments have higher (and possibly considerably higher) values for these parameters than within the ice stream. These values for the ice-stream sediments are consistent with the UpB-type dilatant, deforming-till values where Blankenship

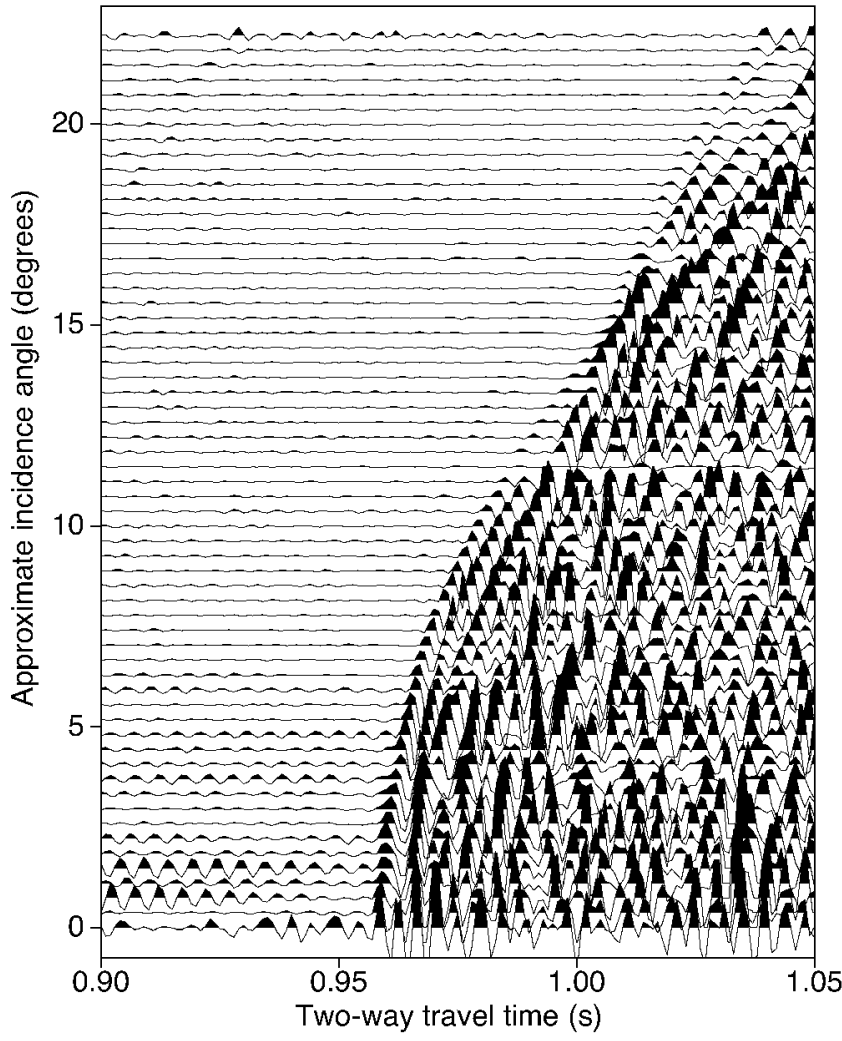

Fig. 4. Plot of a shot record from the ice sheet at location $\mathrm{Km}$ 38.1, over the region of ice-sheet sediments. Each trace is separated by $25 \mathrm{~m}$ : the trace label is approximate angle of incidence at the base of the ice sheet.

and others $(1986,1987)$ determined $\alpha_{2}<1.7 \mathrm{~km} \mathrm{~s}^{-1}$, a high porosity $\phi=0.4$ and low effective pressures.

\subsection{AVO}

These results can be further strengthened by examining the shear-wave velocity in the sediments. As the seismic streamer used in the experiment did not allow direct collection of shear-wave data, we extract that information from the crossing-angle data. Figure 3 is a typical ice-stream example demonstrating the crossing-angle behavior, with traces at near offsets having negative phase, and traces at far offsets having positive phase; I have annotated the figure to show the change in phase across the crossing angle. Contrast this to Figure 4, a shot record from the ice sheet where the reflections are all the same phase. The shot records from the ice sheet all show $R_{\mathrm{p} 0}>0$ and no crossing angle. The poorquality shots at the margin of the ice stream are because of the noise from buried crevasses. In general, the crossing angle could not be localized to better than 3-4 traces (approximately $\pm 1.5^{\circ}$ ). The crossing-angle data (Fig. 5) show considerable scatter, but none are $>13^{\circ}$. The crossing angles near the shear margin are slightly higher than those in the interior, but that difference is only barely significant, and I do not insist upon it. All the shots within the ice stream consistently show a phase reversal.

Several approximations were made in the analysis, but introduce inconsequential errors. We calculate the ice thickness using a four-layer firn velocity model assuming constant thickness along our line, and a constant P-wave velocity of $\alpha_{1}=3831 \mathrm{~m} \mathrm{~s}^{-1}$ below the firn. For simplicity I have replaced the firn with a layer of ice with equivalent vertical travel time, which introduces a small horizontal posi- 


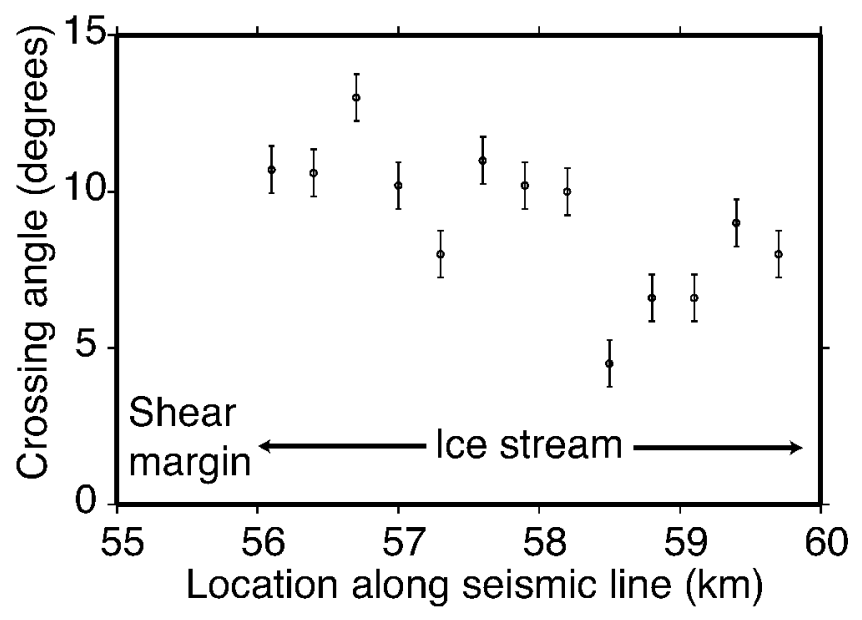

Fig. 5. Plot of the crossing angle $i_{\mathrm{c}}$ along the seismic line. The approximate region of the ice stream (beyond $\mathrm{Km} 56$ ) is indicated. The shear margin is characterized by buried crevasses and a rapid change in ice-flow velocity.

tion error in the source and receiver. The maximum bed slope along our line is approximately $2^{\circ}$ in the ice stream and $4^{\circ}$ in the shear margin, and I can correct for much of that in our angle-of-incidence calculations. The cross-line slopes are not well known, but the airborne radar surveys suggest that they are less steep than the in-line slopes (personal communication from D. D. Blankenship and D. L. Morse, 2001). I estimate the error in our angle of incidence arising from these approximations as $\Delta i= \pm 2^{\circ}$.

In the ice stream, the data show that the reflection changes phase at a mean crossing angle $\overline{i_{\mathrm{c}}}=9.1^{\circ} \pm 2.3$; added to the error in angle-of-incidence determination, I estimate an error $\Delta i_{\mathrm{c}}= \pm 3^{\circ}$. The observed $i_{\mathrm{c}}=9^{\circ}$ suggests that the P-wave velocity $\alpha_{2} \sim 1.7 \mathrm{~km} \mathrm{~s}^{-1}$ (see Fig. 2). A higher $\alpha_{2}$ would make the normal-incidence phase positive $\left(R_{\mathrm{p} 0}>\right.$ 0 ), which is not observed; alternatively, a lower $\alpha_{2}$ would push the zero-crossing angle $i_{\mathrm{c}}$ to the right for all $\beta_{2}$, above what is observed (Fig. 2). For an assumed sediment P-wave velocity of $\alpha_{2}=1.7 \mathrm{~km} \mathrm{~s}^{-1}$, this crossing angle suggests an extremely low S-wave velocity of $\beta_{2}=0.1 \mathrm{~km} \mathrm{~s}^{-1} \pm 0.2$. The value of $\beta_{2} \sim$ $0.1 \mathrm{~km} \mathrm{~s}^{-1}$ is fully consistent with that measured by Blankenship and others $(1986,1987)$ at UpB on Ice Stream B. Our observed P- and S-wave velocities are difficult to explain in any way except through a high-water-pressure, poorly consolidated, soft layer beneath Ice Stream C.

\section{GONGLUSION}

The normal-incidence phase and AVO behavior of the seismic reflection off the base of the ice in the onset region of Ice Stream $\mathrm{C}$ is consistent with a subglacial layer with low Pwave velocity $\alpha_{2}=1.7 \mathrm{~km} \mathrm{~s}^{-1}$ and extremely low S-wave velocity $\beta_{2}=0.1 \mathrm{~km} \mathrm{~s}^{-1}$.

We suggest that this layer is a dilatant and presumably deforming till layer that underlies the ice stream. This dilatancy is well established within a few tens of $\mathrm{km}$ of the onset of the ice stream, as evidenced by the consistency of the AVO effect at all the shots ( $300 \mathrm{~m}$ shot spacing) in the ice stream. This behavior is also consistent with the boundaries of the sedimentary basin determined by refraction shooting (Anandakrishnan and others, 1998). In addition, these reflections are of distinctly different character from reflections off non-ice-stream subglacial sediments and off crystalline basement. We suggest that subglacial till deformation is an important mechanism for the initiation of rapid ice-stream flow.

\section{AGKNOWLEDGEMENTS}

I thank R. B. Alley and two anonymous reviewers for helpful discussions and comments. This research was supported in part by the U.S. National Science Foundation through grants OPP9996262 and OPP9725708.

\section{REFERENGES}

Aki, K. and P. G. Richards. 1980. Quantitative seismology: theory and methods. San Francisco, W.H. Freeman and Co.

Alley, R. B., D. D. Blankenship, C. R. Bentley and S. T. Rooney. 1987a. Till beneath Ice Stream B. 3. Till deformation: evidence and implications. $\mathcal{F}$ Geophys. Res., 92(B9), 8921-8929.

Alley, R. B., D. D. Blankenship, S. T. Rooney and C. R. Bentley. 1987b. Till beneath Ice Stream B. 4. A coupled ice-till flow model. 7. Geophys. Res., 92(B9), 8931-8940.

Anandakrishnan, S., D. D. Blankenship, R. B. Alley and P. L. Stoffa. 1998. Influence of subglacial geology on the position of a West Antarctic ice stream from seismic observations. Nature, 394(6688), 62-65.

Bell, R. E. and 6 others. 1998. Influence of subglacial geolog y on the onset of a West Antarctic ice stream from aerogeophysical observations. Nature, 394(6688), 58-62.

Bindschadler, R., J. Bamber and S. Anandakrishnan. 2001. Onset of streaming flow in the Siple Coast region, West Antarctica. In Alley, R. B. and R. A. Bindschadler, eds. The West Antarctic ice sheet: behavior and environment. Washington, DC, American Geophysical Union, 123-136. (Antarctic Research Series 77.)

Blankenship, D. D., C. R. Bentley, S. T. Rooney and R. B. Alley. 1986. Seismic measurements reveal a saturated porous layer beneath an active Antarctic ice stream. Nature, 322(6074), 54-57.

Blankenship, D. D., C. R. Bentley, S.T. Rooney and R. B. Alley. 1987. Till beneath Ice Stream B. 1. Properties derived from seismic travel times. 7. Geophys. Res., 92(B9), 8903-8911.

Burkett, P. G. 2000. Ice fabric and active seismology: an investigation and interpretation in central West Antarctica. (M.Sc. thesis, Pennsylvania State University.)

Hamilton, E. L. 1976. Shear-wave velocity versus depth in marine sediments: a review. Geophysics, 41(5), 985-996.

Hodge, S. M. and S. K. Doppelhammer. 1996. Satellite imagery of the onset of streaming flow of Ice Streams C and D, West Antarctica. 7. Geophys. Res., 101(C3), 6669-6677.

Joughin, I. and 7 others. 1999. Tributaries of West Antarctic ice streams revealed by RADARSAT interferometry. Science, 286(5438), 283-286.

Nolan, M. and K. Echelmeyer. 1999. Seismic detection of transient changes beneath Black Rapids Glacier, Alaska, U.S.A.: II. Basal morphology and processes. F. Glaciol., 45(149), 132-146.

Sen, V., P. L. Stoffa, I.W. D. Dalziel, D. Blankenship, A. M. Smith and S. Anandakrishnan. 1998. Seismic surveys in centralWest Antarctica: data and processing examples from the ANTALITH field tests (1994-1995). Terra Antartica, 5, 761-772.

Sheriff, R. E. and L. P. Geldart. 1995. Exploration seismology. Second edition. Cambridge, Cambridge University Press.

Shuey, R.T. 1985. A simplification of the Zoeppritz equations. Geophysics, 50(4), 609-614.

Smith, A. M. 1997. Basal conditions on Rutford Ice Stream, West Antarctica from seismic observations. 7. Geophys. Res., 102(B1), 543-552.

Tulaczyk, S., B. Kamb and H. F. Engelhardt. 200la. Estimates of effective stress beneath a modern West Antarctic ice stream from till preconsolidation and void ratio. Boreas, 30 (2), 101-114.

Tulaczyk, S. M., R. P. Scherer and C. D. Clark. 2001b. A ploughing model for the origin of weak tills beneath ice streams: a qualitative treatment. Quat. Int., 86(1), 59-70. 